Acta Crystallographica Section E

Structure Reports

Online

ISSN 1600-5368

Jie $\mathrm{Li}^{\mathrm{a}}$ Jian-Ping $\mathrm{Ma},{ }^{\mathrm{a}} \mathrm{Ru}-\mathrm{Q} \mathrm{i}$ Huang ${ }^{a}$ and Yu-Bin Dong ${ }^{b}$ *

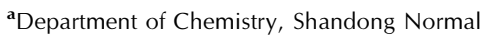
University, Jinan 250014, People's Republic of China, and ${ }^{\mathbf{b}}$ College of Chemistry, Chemical

Engineering and Materials Science, and

Shandong Key Laboratory of Functional

Chemical Materials, Shandong Normal

University, Jinan 250014, People's Republic of

China

Correspondence e-mail:

yubindong@sdnu.edu.cn

\section{6-[4-(2-Chloroethyloxy)naphthyl]fulvene. Corrigendum}

In the paper by Li, Ma, Huang \& Dong [Acta Cryst. (2005), E61, o3901-o3902], the correspondence author is incorrectly indicated. The correct correspondence author is given here, Received 5 November 2005 Accepted 16 November 2005 Online 23 November 2005 